\title{
Feasibility Study of Electromechanical Cylinder Drivetrain for Offshore Mechatronic Systems
}

\author{
D. Hagen ${ }^{1}$ W. Pawlus ${ }^{1}$ M.K. Ebbesen ${ }^{1}$ T.O. Andersen ${ }^{2}$ \\ ${ }^{1}$ Department of Engineering Sciences, University of Agder, N-4898 Grimstad, Norway. \\ E-mail: daniel.hagen,witold.pawlus, morten.k.ebbesen@uia.no \\ ${ }^{2}$ Department of Energy Technology, Aalborg University, 9220 Aalborg East, Denmark. \\ E-mail: toa@et.aau.dk
}

\begin{abstract}
Currently, there is an increasing focus on the environmental impact and energy consumption of the oil and gas industry. In offshore drilling equipment, electric motors tend to replace traditionally used hydraulic motors, especially in rotational motion control applications. However, force densities available from linear hydraulic actuators are still typically higher than those of electric actuators. Therefore, usually the remaining source of hydraulic power is thereby the hydraulic cylinder. This paper presents a feasibility study on the implementation of an electromechanical cylinder drivetrain on an offshore vertical pipe handling machine. The scope of this paper is to investigate the feasibility of a commercial off-the-shelf drivetrain. With a focus on the motion performance, numerical modeling and simulation are used when sizing and selecting the components of the considered electromechanical cylinder drivetrain. The simulation results are analyzed and discussed together with a literature study regarding advantages and disadvantages of the proposed solution considering the design criteria of offshore drilling equipment. It is concluded that the selected drivetrain can only satisfy the static motion requirements since the required transmitted power is higher than the recommended permissible power of the transmission screw. Consequently, based on the recommendation of the manufacturer, avoidance of overheating cannot be guaranteed for the drivetrain combinations considered for the case study presented in this paper. Hence, to avoid overheating, the average speed of the motion cycle must be decreased. Alternatively, external cooling or temperature monitoring and control system that prevents overheating could be implemented.
\end{abstract}

Keywords: Mechatronic systems, offshore drilling, hydraulic actuation systems, electromechanical cylinder, modeling and simulation, multibody systems, motion control.

\section{Introduction}

Since the 1960's, drilling for oil and gas production (well construction) has been carried out in harsh offshore environments like the North Sea. More recently, the drilling process has moved towards operation in ultra deep-water (water depths beyond $1500 \mathrm{~m}$ ) and Arctic areas. Clearly, this has required a significant development of the offshore drilling equipment, especially regarding monitoring and control systems and more advanced heave compensating technology. Hence, developments in automation and safety of machine operation have contributed to increased usage of multidisciplinary technologies. Therefore, design, production and operation of a typical offshore drilling machine requires synthesis of knowledge from various disciplines, such as mechanical engineering, electrical engineering, control theory, hydraulic actuation systems and many more, in short - mechatronics. This is why an increasing number of offshore drilling systems is considered to 
be mechatronic systems and hence, they are referred in this paper to as offshore mechatronic systems (OMS).

The hydraulic actuation systems (drives) used in OMS consist of several hydraulic circuits supplied by a hydraulic power unit (HPU). Hydraulic drives are well known for their high reliability, robust safety features, high power transmission, high load capabilities and good overload protection. In Bak (2014) methods for modeling, parameter identification, design and optimization of an offshore pipe deck (knuckle boom) crane are presented, focusing on accommodating the needs of the system designer. Figure 1 illustrates a typical offshore drilling rig layout.

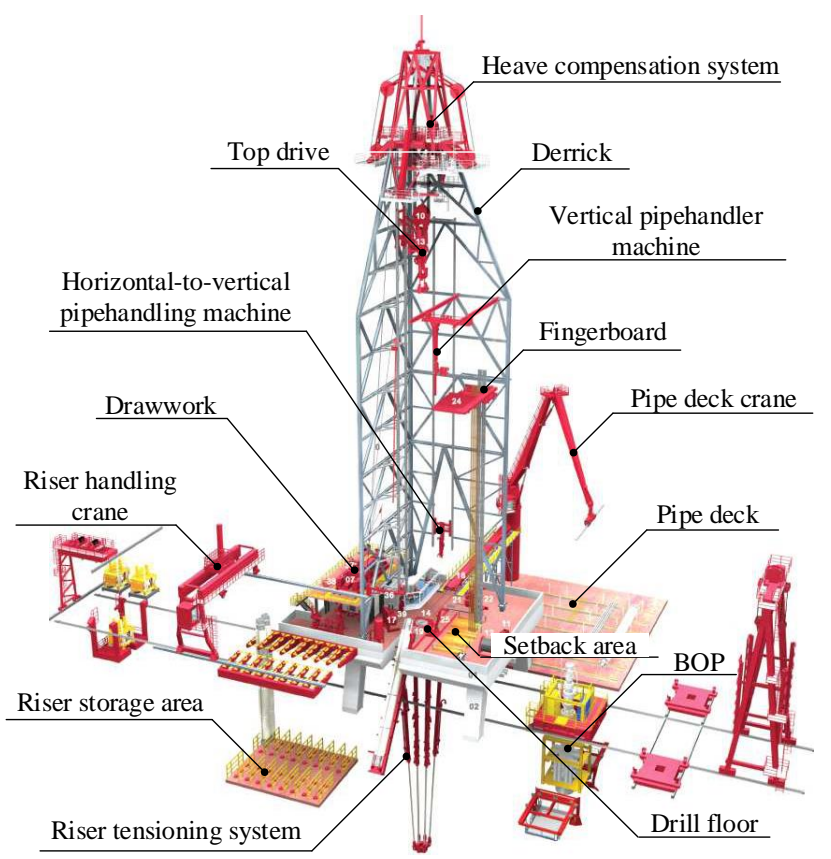

Figure 1: Typical drilling rig layout. Image courtesy of Bak (2014).

Due to an increasing focus on the environmental footprint and energy consumption, offshore oil and gas industry is experiencing a shift in drive systems as highly efficient electric drives tend to replace less efficient hydraulic drives. A review of drive systems encountered in offshore drilling applications is presented by Pawlus et al. (2016a), specifically focusing on giving a comparison of hydraulic and electric rotary drivetrains along with detailed explanations of their advantages and drawbacks.

Currently, the shift from the traditionally used hydraulic motors to electric motors is observed in an increasing number of applications, e.g. top-drive, drawwork, and pipe handling machines. However, the possibility of using both electrical motors and hydraulic cylinders on multi-functional machinery proves to combine some excellent characteristics from the two branches of actuation technology. To fully benefit from such a hybrid drive solution, there is a need for linear drives capable of operating free of a central HPU, i.e. self-contained with power supplied via electrical wiring.

In other industries, hydraulic cylinders are successfully replaced by self-contained electromechanical cylinder (EMC) drivetrains which increase energyefficiency and motion accuracy in some applications. The modular self-contained design offers advantages such as plug and play installation and low maintenance. In many industries, disadvantages like increased wear, inadequate overload protection, and decreased load capabilities are accepted. There is, however, insufficient research conducted that compares the electrohydraulic cylinder with valve control (EHC) against the EMC drivetrain for the design criteria which characterize OMS.

A literature survey on this topic shows that there is little available scientific research comparing EMC drivetrains and EHC systems for the harsh environment and load spectra of OMS. Furthermore, the closest research topics found in literature come from the aircraft and aerospace industries. Since the late 1970's, several research and development projects, with such topics as e.g. More Electric Aircraft and Power-byWire-Technology, consider future technology for aircraft flight control systems, aiming to reduce the overall system weight, as well as installation and maintenance effort, according to Frischemeier (1997). Thus, research on replacing traditional EHC systems with EMCs in aircraft flight control and aerospace systems is well documented in literature.

Comparative analysis of different types of mechanical screw transmissions (ball-screw and roller screw) and their design regarding reliability (fail safe modes) is presented by Bodden et al. (2007) and Garcia et al. (2008). To diagnose the condition of an EMC drivetrain, Balaban et al. (2009) demonstrate diagnostic algorithms for aerospace systems. In Narasimhan et al. (2010), an approach that combines the analytical model-based and feature-driven diagnosis approaches for the detection and isolation of single faults is presented.

In addition, a significant number of web articles that compare EMC drivetrains with EHC systems regarding pros and cons can be found on the Internet - a few representative topics are Hydraulic vs. Electromechanical Actuators and Choosing Between Electromechanical and Fluid Power Linear Actuators in Industrial Systems Design.

More comprehensive literature discussing the screw transmission itself is also of relevance to this study. A dynamic load test using large load, high bandwidth, 
hydraulic actuation to generate load profiles under force control is demonstrated in Schinstock and Haskew (1996). In Lemor (1996), the efficiency of a screw transmission and the means to improve it and maintain it for the life of the component are discussed and different modes of failure and their most common order of appearance, cases of failures and analysis of those failures are presented. The capabilities and limitations of a roller screw with emphasis on slip tendency is presented in Hojjat and Mahdi Agheli (2009).

Through the above brief survey it is indicated that design and operation of EMC drivetrains for offshore drilling applications are relatively new and yet undiscovered research directions. Therefore, this paper presents a feasibility study of the implementation of an EMC drivetrain in a case study of an offshore vertical pipe handling machine. The scope of this paper is to size and select a commercial off-the-shelf EMC drivetrain from a manufacturer catalog and model the selected drive components based on the information available in a data sheet. State-of-the-art hydraulic actuation systems for offshore drilling applications together with the design criteria and challenges of offshore equipment systems are introduced in Section 2. A modeling and simulation case study is presented in Section 3. Section 4 describes the main components of an EMC drivetrain, sizing principles, and how the EMC drivetrain is modeled. The simulation results are presented in Section 5. Firstly, the system loads and motion cycle of the case study are analyzed to dimension the EMC drivetrain components. Secondly, the component combinations when considering both technical and economic factors based on the sizing principles are selected, and the prescribed motion cycle is simulated. Finally, in Section 6, the simulation results are analyzed, and the motion performance is discussed together with a literature study regarding reliability, safety, and durability of an EMC drivetrain, especially focusing on the design criteria of offshore drilling equipment. The last section contains the conclusion.

\section{Actuation of Offshore Mechatronic Systems}

Modern offshore drilling equipment systems are considered fully mechatronic systems, and state-of-theart offshore drilling rigs are often referred to as cyber drilling rigs. OMS include a broad range of highly specialized machines that are used to perform different operations. Beside subsea and pressure control equipment - e.g the BOP (blowout preventer) - the remaining equipment is referred to as topside equipment. A typical drilling rig layout is illustrated in Figure 1. The scope of this paper is to investigate the motion performance of an EMC drivetrain in order to verify if commercial off-the-shelf drives are viable alternative to traditional hydraulic linear drives in OMS.

\subsection{Hydraulic Actuation Systems}

Normally, the hydraulic actuation system used in OMS consists of several hydraulic circuits supplied by a hydraulic power unit (HPU) with constant supply and return pressures. Together with the control system, the circuits of the actuation system make up a number of motion control sub-systems, each controlling one degree of freedom (DOF). Figure 2 illustrates a simplified schematics of a typical EHC motion control subsystem often used in OMS. It consists of a hydraulic cylinder with integrated position sensor, counterbalance valve and a directional control valve as the main components of the EHC system. The linear motion is controlled with the directional control valve which controls the flow into either of the two cylinder chambers. When the EHC is exposed to negative loads, i.e. piston velocity and load have the same direction, the outlet pressure of the cylinder also needs to be controlled. This is usually handled by the counterbalance valve, which provides a relief valve functionality on the outlet side of the cylinder assisted by the pressure on the inlet side. Depending on the application, negative loads can occur in both directions of motion. In these cases, a counterbalance valve is required on both the piston side and the rod side of the cylinder. Counterbalance valves exist in different variations, e.g. externally vented, non-vented and relief compensated, depending on the various applications they are used for (Bak, 2014). The counterbalance valve serves multiple purposes such as (Sørensen, 2016):

- leak tight load holding

- load holding in case of hose failure

- overload protection

- shock absorption

- cavitation prevention at load lowering

- no drop before lift.

In a hydraulic system where the HPU powers more than one hydraulic actuator, most often a pressure compensated directional control valve with electrohydraulic actuation is used. Such a valve gives a load independent flow control which reduces the requirements for the control system. Also, closed loop spool position control is often used in applications where high position and velocity accuracy are necessary. 
A typical EHC motion control strategy relies on position feedback from an individual DOF and typically consists of the following elements:

- human-machine interface (HMI)

- set point generator (SPG)

- feedforward controller (FFC)

- feedback controller (FBC).

Apart from the cranes, most of the equipment shown in Figure 1 is operated from operator stations (drilling chairs) located in the drilling control room with a direct view of the equipment located on the drill floor. Besides monitors, push buttons and switches, the operator stations contain two joysticks which the operator uses to generate command signals for the control system. Joystick signals are fed to the SPG where they may be treated in different ways depending on the selected control mode. In open loop control mode, the joystick signal $u_{J S}$ is fed directly to the directional control valve as a feedforward signal (Bak and Hansen, 2013) - see Figure 2.

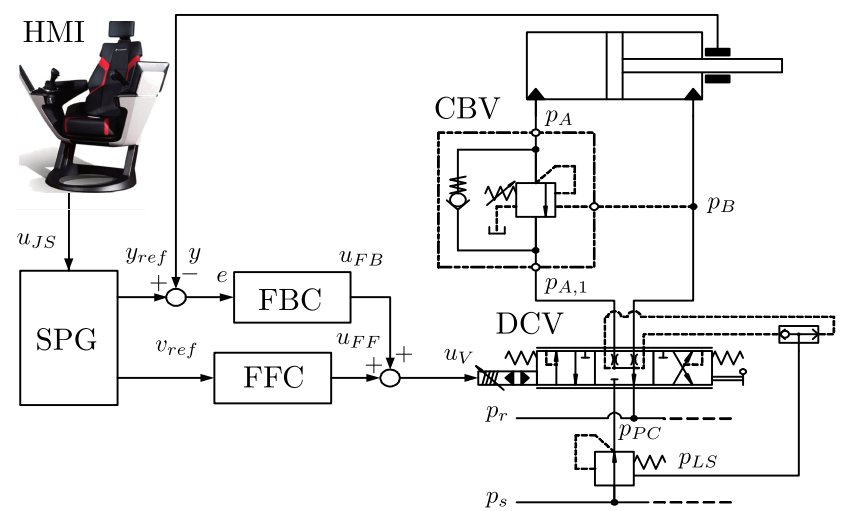

Figure 2: EHC motion control sub-system. Image courtesy of Bak and Hansen (2013).

In closed loop control mode, joystick signals are transformed into velocity and position references for the EHC motions. The latter is used for path control of the tool point, e.g. on a crane where often several DOFs are controlled in a coordinated manner. The FFC is a scaling of the velocity reference $v_{r e f}$, and the FBC is usually a PI controller which compensates for disturbances and accumulated position errors $e=y_{r e f}-y$. The control system usually also contains an element that compensates for the deadband of the directional control valve. The system architecture, as shown in Figure 2, is a popular structure because of its simple and, consequently, robust design. Furthermore, the controllers are relatively easy to tune because of the load-independent flow control (Bak, 2014).

\subsection{Electrification of Powertrains of OMS}

Due to an increasing focus on the environmental impact and reducing the energy consumption, alternating current $(\mathrm{AC})$ motor drives tend to replace hydraulic motors, resulting in advantages such as increased accuracy and energy efficiency, reduced maintenance, and elimination of fluid spills, according to Pawlus et al. (2016a).

However, because of the traditional prevalence of hydraulic drives over electric actuators in translational motion control applications (mainly related to higher force densities available from the former solution), the remaining hydraulic drives on majority of offshore drilling equipment are thereby the hydraulic cylinders (Pawlus et al., 2016a). On the other hand, rotational motion control applications are being gradually dominated by electric motor drives, as illustrated by numerous examples from marine, and oil and gas industries. Obviously, the latter solution is not free of drawbacks. Some of the most typical problems associated with AC motor drives (apart from lower force/torque density) are: the need to use fail-safe brakes (to hold the load when the electrical power is lost), hazardous operation at high load and low speeds (due to reduced cooling capacity and risk of stall conditions), as well as the demand to invest in additional components that would decrease the harmonics or provide for extra cooling (Pawlus, 2016).

More specifically, the shipping sector has developed an interest in using variable speed AC drives for ship propulsion applications (Sakuraba et al., 1992). Similarly, all-electric vessels and dynamic positioning (DP) systems are the concepts that contribute to an increased popularity of electric motors due to the lowered energy consumption, smooth and silent operation, as well as improved controllability properties that they offer compared to traditional hydraulic systems (Yadav et al., 2014). Also, the percentage share of electric actuation systems in oil and gas production units constantly increases, according to Rahimi et al. (2011) and Gallant and Andrews (2006).

Recently, the company Robotic Drilling Systems AS successfully tested their robotic pipe handler. This machine is all-electric and offers features such as handling of pipes from horizontal to vertical position and spinning capability (Austigard, 2016). Furthermore, the machine is self-contained (with integrated hardware control) and offers advantages of being easy to install and automatic exchange of grippers, e.g. for large casing sizes. In addition, a fully electric roughneck and a drill floor robot is in their portfolio. Common for these three machines is that they have entirely abandoned the use of linear drives for motion.

Due to self-contained systems being increasingly 
more available, the current benefit of a central HPU will become less attractive in the future. For the offshore industry to follow this trend and still integrate translational motion control in the OMS, there is a need to look at alternative linear drive solutions to the existing hydraulic systems. This is also motivated by the fact that an increasing number of attempts is reported in various industries to replace hydraulic linear drives with all-electric substitutes, as mentioned by Isermann et al. (2002) or Holm et al. (2013). In particular, permanent magnet linear actuators are promising due to the higher force levels they offer, especially when they are combined with additional solutions to increase the provided force even further, such as a double gas spring described by Ummaneni et al. (2007).

\subsection{Design Criteria and Challenges}

OMS are characterized by a high price, high level of system complexity and low production numbers, according to Bak (2014). Furthermore, in the offshore industry, there are very limited opportunities to build prototypes for verification of the design. Consequently, this requires a significant level of skill and experience to develop and design such systems. Also, due to market competition from conventional low-cost solutions, the focus on manufacturing and development costs is constantly increasing. Hence, the system designers continuously have to improve their design procedures regarding sizing and selection of technical solutions, components, and materials to obtain the best possible tradeoff between a wide range of design criteria in an efficient way. Due to the remote location of the drilling platform and high cost of production downtime, reliability and productivity become the most critical performance requirements.

Apart from such obvious design criteria for OMS as displacement, speed and power requirements dictated by the considered application, there are also other challenges exclusively associated with the electrical actuation systems of OMS, according to Pawlus (2016). One of them is to apply harmonics mitigation measures in electric motor drives to prevent voltage notches and overvoltage ringing that can damage the installation and cause threat to personnel offshore (Hoevenaars et al., 2013). In addition, vibration and fatigue damage pose a serious danger to rotating components (e.g. bearings) of any drivetrain. Therefore, the techniques which help to monitor the condition of these elements are becoming increasingly popular, not only in offshore drilling industry (Kandukuri et al., 2016). According to Pawlus et al. (2016b), a solution to lower the associated fatigue and vibration damage is to use smoother motion profiles which are tailor-made for a given application (Pawlus et al., 2016b).
Likewise, selection of the appropriate electric motor type, i.e. induction or permanent magnet, is also considered to be a challenge (Couper et al., 2012). In general, simplicity, robust construction, and relative ease of certification for safe operation in explosive atmospheres (European Commission, 2014) make induction motors exceptionally popular on offshore drilling rigs. However, according to Neleman (2009), the number of Ex certified permanent magnet synchronous motors (PMSMs) is increasing. The use of synchronous machines is mainly motivated by their higher efficiencies and higher torque densities as compared to induction motors, which opens a possibility to reduce the size of the gearbox or even apply a direct drive solution.

Similarly, optimal design of electric powertrains and reduction of unnecessary conservatism when sizing the components is a topic which has proven to generate significant cost- and time-savings in the product development process (Pawlus et al., 2015). When applying the optimal design techniques, not only the dimensioning process itself is improved but also the operating point of the resulting drivetrain can be moved closer to the constraints allowing to utilize the power available from the energy source more efficiently. A complementary approach to designing tailor-made actuation systems is presented in Pawlus et al. (2016c) and is based on thermal modeling of electric actuation systems to avoid using rules of thumb concerning the allowable overloads of EMC drivetrains.

Finally, factors such as safety and environment, cost, maintenance, operation in sensitive regions, potential of automation, and applicability to subsea infrastructure should all affect selection of the most suitable components of actuation systems of OMS - refer to Pawlus et al. (2016a) and the references therein for a more detailed discussion on the above topics.

\subsection{Summary}

Although the hydraulic actuation systems have established a good track record in the offshore drilling industry (especially when translational motion control is considered), there is observed a growing number of examples where electric motor drives become a tough competitor to this traditional solution. Although there are many case studies in the literature devoted to the superiority of variable speed AC motor drives over hydraulic powertrains in rotational motion control, the research related to the feasibility studies of linear electric actuators in offshore drilling applications is still limited. Hence, this paper presents an analysis of practicability of the implementation of an EMC drivetrain in an offshore pipe handling machine. 


\section{Considered System - Vertical Pipe Handling Machine}

The SmartRacker (SR) of Cameron Drilling Systems is used in this paper as a case study for analyzing the feasibility of implementing an EMC drivetrain. The SR is a column type multipurpose pipe (drill-pipe, drillcollar and casing) handling machine that combines the functionality of several traditional pipe handling machines in one machine.

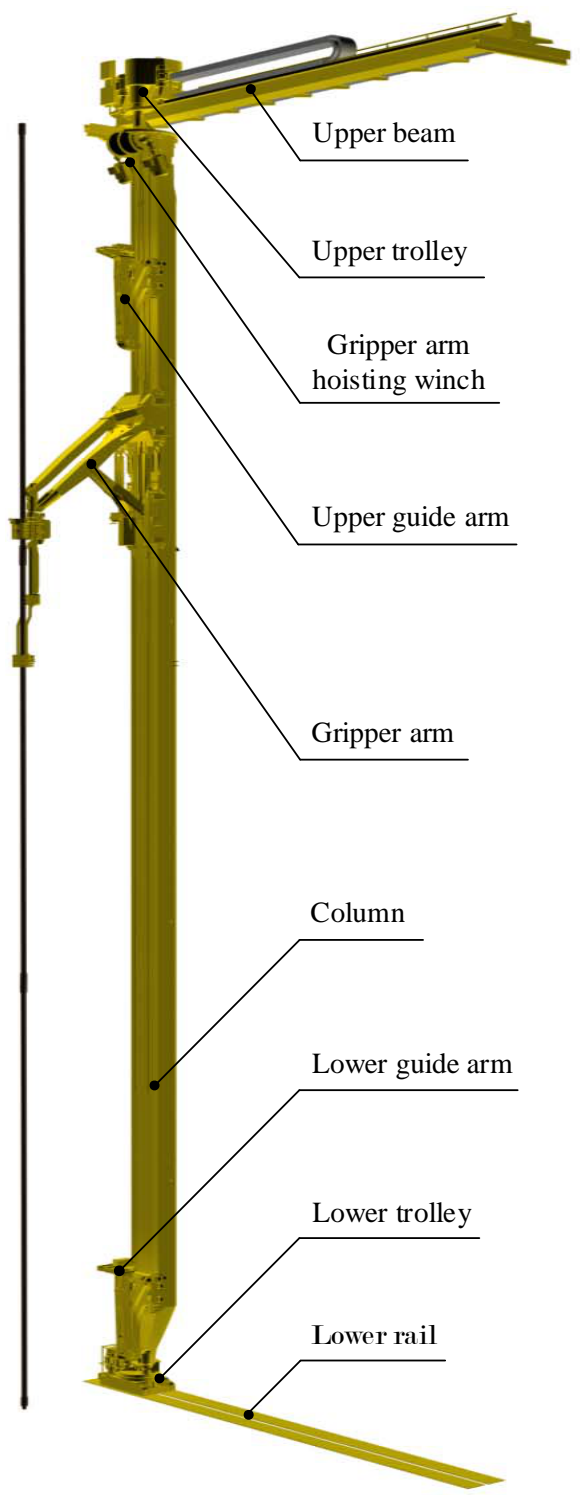

Figure 3: Illustration of the SmartRacker - courtesy of Cameron Sense AS.

The SR can perform the following tasks:

- move stands (two or more joints of pipe connected) between well center and fingerboard
- building of stands for storage inside the fingerboard while drilling

- handling of a single pipe from horizontal to vertical position and vice versa

- lifting operation on drill floor, i.e. the gripper arm can be used as a crane.

As illustrated in Figure 3, the column is supported at the upper beam and lower rail by a track and a rack and pinion system. The lower rail is mounted directly on the drill floor, whereas the upper beam is connected to the structure of the derrick, as shown in Figure 1. In both ends of the column there are located AC motor actuated trolleys that allow for horizontal movement of the machine along the tracks.

The column includes upper and lower guide arms they are designed to guide the stand, i.e. guide the top and bottom of the pipe being in motion. The arm located in the middle is the gripper arm, responsible for holding the pipe in a secure grip. The AC motor actuated winch located on top of the column is used to hoist or lower the gripper arm. All arms are equipped with an EHC which allows for the extension and retraction in order to position a stand in the finger board or well center. The AC slew motors located on the lower trolley make it possible for the whole machine to rotate about its vertical axis. A comprehensive study on the hoisting winch similar to the gripper arm hoisting winch of the SR is presented in the work done by Pawlus (2016).

In this work, the gripper arm, presented in Figure 4, of the vertical pipe handling machine (Figure 3) is used as a modeling and simulation case study. It is chosen due to the potential to replace the hydraulic linear drive by a more accurate, efficient and environmentally friendly solution.

\subsection{Kinematic Structure}

The gripper arm is modeled as a planar multibody system using governing equations based on (Nikravesh, 1988) and (Nikravesh, 2008). In total, the model consists of 10 rigid bodies, including the hydraulic lifting cylinder and the pipe (load) connected to the gripper head, as illustrated in Figures 4 and 5. Body 7 includes both the gripper head and the rod of the hydraulic soft stabbing cylinder. The 10 bodies are interconnected by 13 kinematic joints as described in Table 1.

The three body coordinates $\left(x_{b}, y_{b}, \phi_{b}\right)$ are the coordinates of the local reference plane attached to the mass center of the bodies, while the origin of the global reference plane is defined on the drill floor - see Figure 5 . 


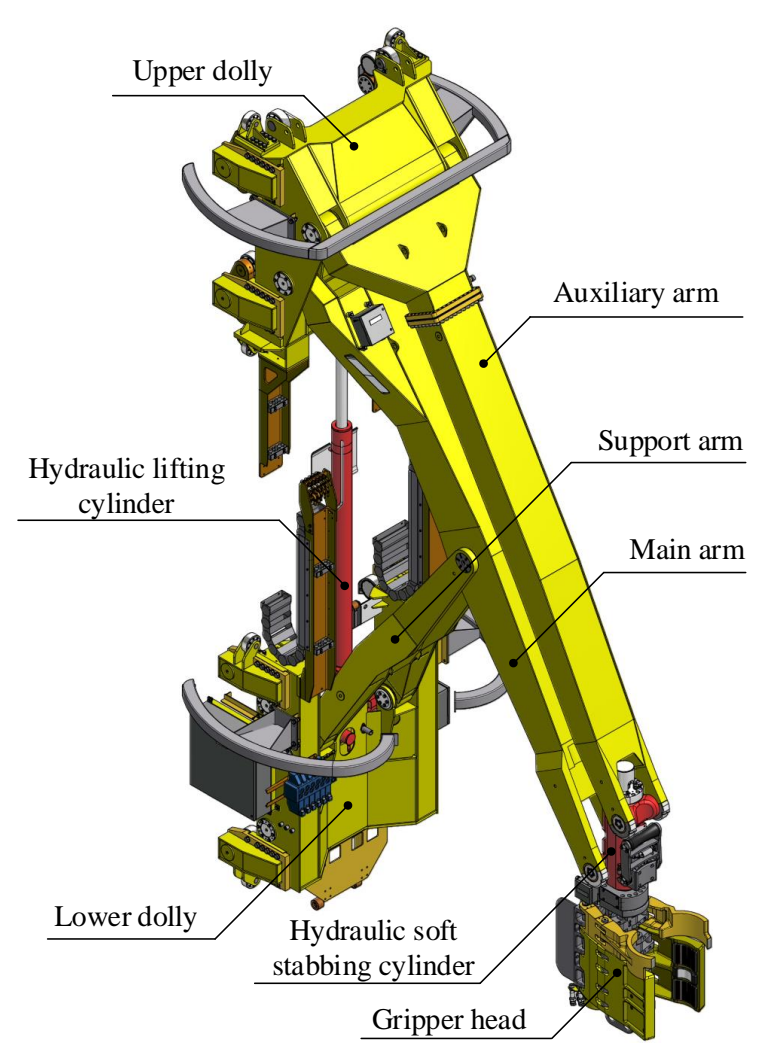

Figure 4: SmartRacker@ gripper arm - courtesy of Cameron Sense AS.

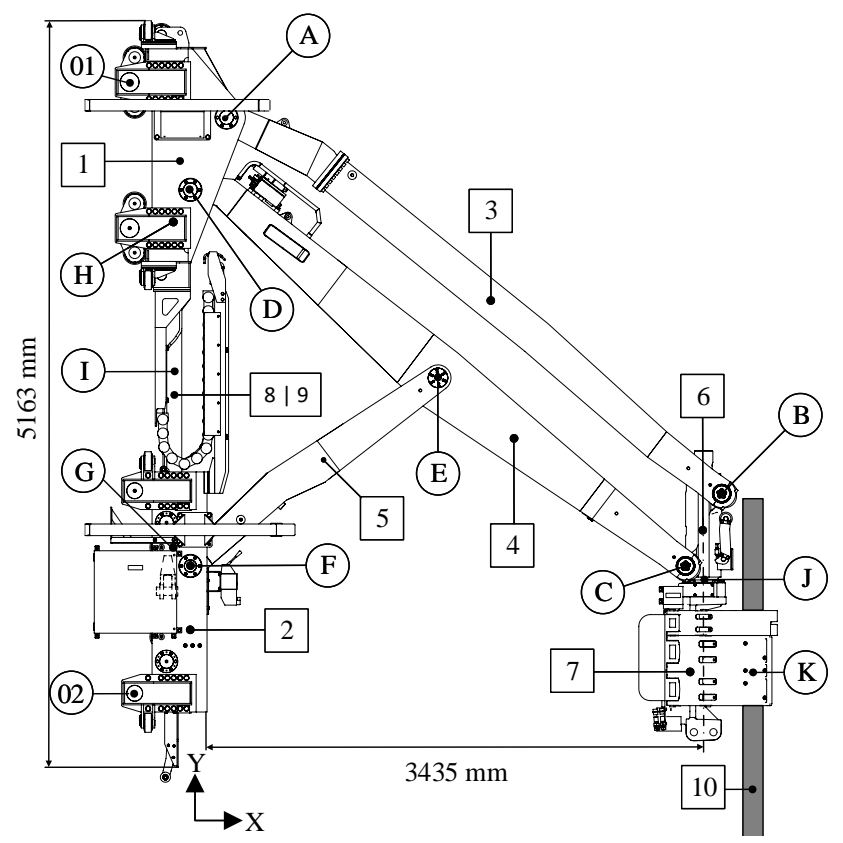

Figure 5: Gripper arm in fully extended position courtesy of Cameron Sense AS.
Table 1: Kinematic constraints

\begin{tabular}{cl}
\hline Constraint & Description \\
\hline 01 & Translational joint, column - body 1 \\
02 & Fixed constraint, column - body 2 \\
A & Revolute joint, body $1-3$ \\
B & Revolute joint, body $3-6$ \\
C & Revolute joint, body $6-4$ \\
D & Revolute joint, body $4-1$ \\
E & Revolute joint, body $4-5$ \\
F & Revolute joint, body $5-2$ \\
G & Revolute joint, body $2-8$ \\
H & Revolute joint, body $1-9$ \\
I & Translational joint, body $8-9$ \\
J & Fixed constraint, body $6-7$ \\
K & Fixed constraint, body $7-10$ \\
\hline
\end{tabular}

\subsection{Inverse Dynamics}

To investigate the force that has to be delivered by the lifting cylinder, and the reaction force arising, the following inverse dynamic analysis is performed. A motion cycle logged from an offshore oil rig in operation is assumed to be an input function to the longitudinal driver constraint representing the hydraulic lifting cylinder.

The equations of motion for a planar system consisting of $b$ bodies containing $m=3 b$ coordinates interconnected by kinematic joints can be written as:

$$
\mathbf{M} \ddot{\mathbf{q}}=\mathbf{g}^{e x t}+\mathbf{g}^{c}
$$

where $\mathbf{M}$ is the $30 \times 30$ mass/inertia matrix:

$$
\mathbf{M}=\left[\begin{array}{ccccccc}
m_{1} & 0 & 0 & 0 & 0 & 0 & 0 \\
0 & m_{1} & 0 & 0 & 0 & 0 & 0 \\
0 & 0 & J_{1} & 0 & 0 & 0 & 0 \\
0 & 0 & 0 & \ddots & 0 & 0 & 0 \\
0 & 0 & 0 & 0 & m_{10} & 0 & 0 \\
0 & 0 & 0 & 0 & 0 & m_{10} & 0 \\
0 & 0 & 0 & 0 & 0 & 0 & J_{10}
\end{array}\right]
$$

and $\ddot{\mathbf{q}}$ is the $30 \times 1$ vector containing the acceleration of the $m$ coordinates. The external forces $\mathbf{g}^{\text {ext }}$ are the $30 \times 1$ vector containing the gravity forces acting on the bodies, and $\mathrm{g}^{c}$ is the $30 \times 1$ vector containing the reaction forces in the constraints. The $b$ bodies in the system must satisfy the equations of motion, but at the same time they must also satisfy a set of $m=3 \cdot 10=30$ independent constraint equations:

$$
\boldsymbol{\Phi}^{30 \times 1}(\mathbf{q}, t)=\left[\begin{array}{c}
\boldsymbol{\Phi}^{29 \times 1}(\mathbf{q}) \\
\boldsymbol{\Phi}^{d}(\mathbf{q})-f(t)
\end{array}\right]=\mathbf{0} .
$$


The position constraint in the form of Equation 3 is a $30 \times 1$ vector containing the kinematic constraints $\boldsymbol{\Phi}(\mathbf{q})$, as described in Table 1, and the one-DOF longitudinal driver constraint $\boldsymbol{\Phi}^{\mathbf{d}}(\mathbf{q}, t)$ that produce a displacement between body 8 and 9 . The motion cycle obtained from the rig is mimicked by the longitudinal driver function represented by $f(t)$. For position analysis, the constraint vector in Equation 3 is solved numerically using the Newton-Raphson method.

The velocity and acceleration constraints are defined in the following equations:

$$
\begin{gathered}
\dot{\boldsymbol{\Phi}}^{30 \times 1}(\mathbf{q}, t)=\left[\begin{array}{c}
\mathbf{D} \dot{\mathbf{q}} \\
\mathbf{\Phi}^{d} \dot{\mathbf{q}}-\dot{f}(t)
\end{array}\right]=\mathbf{0} \\
\ddot{\boldsymbol{\Phi}}^{30 \times 1}(\mathbf{q}, t)=\left[\begin{array}{c}
\mathbf{D} \ddot{\mathbf{q}}+\dot{\mathbf{D}} \dot{\mathbf{q}} \\
\mathbf{\Phi}^{d} \ddot{\mathbf{q}}+\dot{\mathbf{D}}^{d} \dot{\mathbf{q}}-\ddot{f}(t)
\end{array}\right]=\mathbf{0}
\end{gathered}
$$

where $\mathbf{D}$ and $\mathbf{D}^{d}$ make up the $30 \times 30$ Jacobian matrix $\boldsymbol{\Phi}_{\mathbf{q}}$. The terms $\dot{\mathbf{D}} \dot{\mathbf{q}}$ and $\dot{\mathbf{D}}^{d} \dot{\mathbf{q}}$ are referred to as the right hand side of the kinematic acceleration equations, and are represented as:

$$
\begin{gathered}
\gamma=-\dot{\mathbf{D}} \dot{\mathbf{q}} \\
\gamma^{d}=-\dot{\mathbf{D}}^{d} \dot{\mathbf{q}}
\end{gathered}
$$

From Equations 4 and 5, the velocity and acceleration can be found by solving the following expressions:

$$
\begin{gathered}
\dot{\mathbf{q}}=\boldsymbol{\Phi}_{\mathbf{q}}{ }^{-1}\left[\begin{array}{c}
\mathbf{0} \\
\dot{f}(t)
\end{array}\right] \\
\ddot{\mathbf{q}}=\mathbf{\Phi}_{\mathbf{q}}{ }^{-1}\left[\begin{array}{c}
\gamma \\
\gamma^{d}+\ddot{f}(t)
\end{array}\right] .
\end{gathered}
$$

The sum of reaction forces in the constraints can be expressed by the following equation:

$$
\mathrm{g}^{c}=\boldsymbol{\Phi}_{\mathbf{q}}^{\mathbf{T}} \boldsymbol{\lambda}
$$

where $\boldsymbol{\Phi}_{\mathbf{q}}^{\mathbf{T}}$ is the transpose of the Jacobian matrix and it is nonsingular as the constraint equations are linearly independent, and $\boldsymbol{\lambda}$ is a vector containing Lagrange multipliers that are the coefficients in the linear combination. Finally, Equations 1 and 10 are rearranged in order to solve for $\boldsymbol{\lambda}$ :

$$
\boldsymbol{\lambda}=\left(\mathbf{\Phi}_{\mathbf{q}}^{\mathbf{T}}\right)^{-1}\left(\mathbf{M} \ddot{\mathbf{q}}-\mathbf{g}^{e x t}\right)
$$

\subsection{Forward Dynamics}

Unlike the inverse dynamic analysis where the prescribed motion of the driving coordinates determines the motion of the system, in forward dynamic analysis it is the applied forces and moments that are used to determine the motion (Nikravesh, 2008). Consequently, the longitudinal driver constraint is removed, resulting in a $29 \times 30$ Jacobian matrix $\boldsymbol{\Phi}_{\mathbf{q}}$.

The system of constrained bodies can be solved by the following expression:

$$
\left[\begin{array}{c}
\ddot{\mathbf{q}} \\
\lambda
\end{array}\right]=\left[\begin{array}{cc}
\mathbf{M} & -\boldsymbol{\Phi}_{\mathbf{q}}^{\mathbf{T}} \\
\mathbf{\Phi}_{\mathbf{q}} & \mathbf{0}
\end{array}\right]^{-1}\left[\begin{array}{c}
\mathbf{g}^{e x t} \\
\gamma
\end{array}\right]
$$

To introduce displacement in the lifting cylinder, the output of the EMC drivetrain, presented in Section 4.3, is connected as an external force $F_{E M C}$ to bodies 8 and 9 , as expressed in the following equation:

$$
\mathbf{g}^{e x t}=\left[\begin{array}{c}
F_{1, x} \\
F_{1, y} \\
M_{1, \phi} \\
\vdots \\
F_{8, x} \\
F_{8, y} \\
M_{8, \phi} \\
F_{9, x} \\
F_{9, y} \\
M_{9, \phi} \\
F_{10, x} \\
F_{10, y} \\
M_{10, \phi}
\end{array}\right]=\left[\begin{array}{c}
0 \\
-m_{1} g \\
0 \\
\vdots \\
0 \\
-m_{8} g-F_{E M C} \\
0 \\
0 \\
-m_{9} g+F_{E M C} \\
0 \\
0 \\
-m_{10} g \\
0
\end{array}\right] .
$$

In the forward dynamic analysis, the equations of motion expressed in Equation 12 are second-order differential equations and they are solved numerically.

\section{Electromechanical Cylinder Drivetrain}

The EMC drivetrain is a modular linear drive powered by a drive unit, including a servo motor and converter. A transmission system, including a transmission screw and transmission elements e.g. gearbox (optional), timing-belt side drive or flange and coupling converts the rotary motion to translation - see Figure 15. The main components of an EMC drivetrain are illustrated in Figure 6.

To better describe the properties of an EMC drivetrain, the heavy-duty (EMC-HD) version produced by Bosch Rexroth (2015) is chosen as an exemplary drive. Due to its specific characteristics, the EMC-HD 
offers advantages in terms of accuracy, dynamics and controllability, and is developed for use in heavy load applications. An overview of its key technical data is presented below according to Bosch Rexroth (2015):

- basic dynamic load rating: 50 to $470 k N$

- axial force: up to $290 k N$ (tension/compression)

- maximum traversing speed: $1 \frac{\mathrm{m}}{\mathrm{s}}$

- stroke: up to $1700 \mathrm{~mm}$

- protection class: IP65.

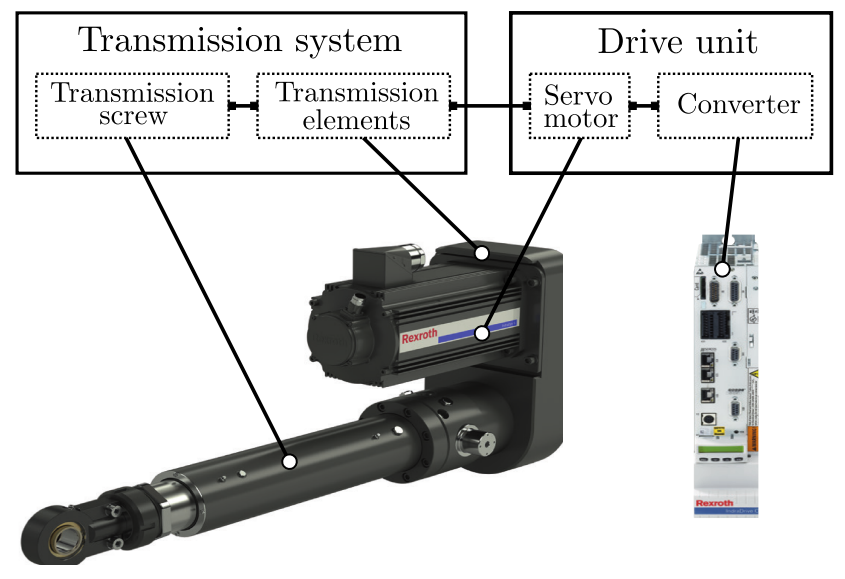

Figure 6: Bosch Rexroth EMC-HD drivetrain with motor attachment via timing belt side drive. Image courtesy of Bosch Rexroth (2015).

The design is completely modular with an integrated planetary roller screw (PRS) or recirculation ball screw transmission. According to Bosch Rexroth (2015), the EMC-HD is designed for cost-efficient work, even under tough conditions and is suited for bending, lifting, pressing and transporting applications.

Hence, the EMC-HD from Bosch Rexroth (2015) is considered as one of the commercial off-the-shelf EMC drivetrain which closely matches the power (static and dynamic force) and motion performance (displacement length and speed) demand of the case study.

\subsection{Transmission Screw}

A transmission screw is a widely used mechanism to convert the rotational motion into the translational one. To increase the accuracy of the transmission screw, it is preferred to omit the sliding between the screw shaft and nut. Therefore, transmission screws with rolling elements such as ball screw and roller screw are introduced (Hojjat and Mahdi Agheli, 2009).

In comparison to the hydraulic cylinder, the precision of ball screw and roller screw is high because the phenomenon of stick-slip is eliminated due to the absence of sliding. One of the areas where friction in hydraulic cylinders represents a constant challenge is in OMS, according to Ottestad et al. (2012). Also, in comparison to the traditional lead screw, the backlash phenomenon can be eliminated by preloading the nut, which lowers the axial deflection and increases the stiffness, according to Hojjat and Mahdi Agheli (2009). Due to the increased diameter and the number of contact surfaces, the roller screw, according to Schinstock and Haskew (1996), is well suited for applications where the loads are large and have a significant shock load content compared to the ball screw.

The roller screw exists in three different designs: planetary, differential planetary and recirculating roller screw. All three designs include the following three elements, as shown in Figure 7: a threaded screw shaft, a threaded or grooved nut and a set of threaded or grooved rollers which engage with both the shaft and the nut (Lemor, 1996).

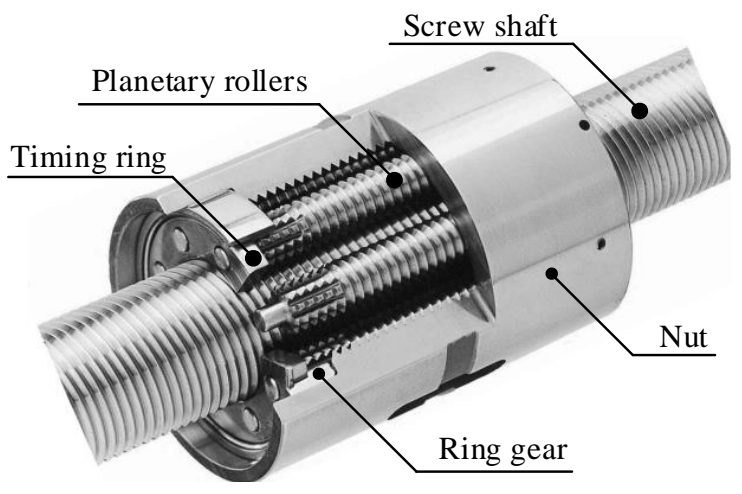

Figure 7: Planetary roller screw (PRS) main components. Image courtesy of Parker (2013).

In most EMC drivetrains, the PRS design is used, according to Lemor (1996). The reason for this is an inherent capacity of PRS to withstand very high accelerations and speeds and its ability to handle heavy loads for a long time. This capability places the PRS between large ball screws and hydraulic cylinders. According to Lemor (1996), PRS compares favorably over ball screws and hydraulic cylinders because its resistance to adverse environment is higher than that of ball screws and the EMC drivetrains is not prone to fluid spills.

\subsection{Sizing Principles}

To make sure that the EMC drivetrain can deliver sufficient performance when considering both technical and economical factors, the selection of the EMC drivetrain components has to be made early in the design phase 
of the complete machine. Also, when sizing the EMC drivetrain, it is important to define the system requirements regarding load, speed, and acceleration of the complete motion cycle. According to Bosch Rexroth (2015), the key parameters that have decisive influence on the final solution are:

1. Load: process forces, masses, duty cycle, service life requirements.

2. Dynamics: acceleration, linear speed, cycle time.

3. Geometry: work space, installation space, stroke length, interference elements.

4. Environmental and installation conditions: mounting orientation, degrees of freedom, temperature, humidity, contamination, vibration and shocks.

According to Bosch Rexroth (2015), the type of screw transmission, lead, gear reductions and drive unit can be selected such that the requirements are met precisely and efficiently by stating the acceleration and linear speeds as accurately as possible. A reliable EMC drivetrain solution can be found when the loads are known as accurately as possible. The average load $F_{m}$ over the entire cycle can be determined when knowing all occurring forces in the application over the entire stroke length.

The average load forms the basis for the nominal life calculation of the EMC drivetrain. When the EMC drivetrain configuration is selected, the dynamic load capacity $C$ can be found in the catalog (Bosch Rexroth, 2015) and the nominal life in number of revolutions and hours can be calculated from the following equations:

$$
\begin{gathered}
\left.L_{10}=\left(\frac{C}{F_{m}}\right)^{3} 10^{6} \text { [revolutions }\right] \\
L_{10 h}=\frac{L_{10}}{n_{m}}[\text { hours }] \\
n_{m}=\frac{v_{m}}{P_{P R S}}[\text { rpm }]
\end{gathered}
$$

where $v_{m}$ is the average linear speed and $P_{P R S}$ is the lead (linear movement due to screw) of the PRS.

Considering the power losses, a permissible mechanical drive power is stated in the catalog (Bosch Rexroth, 2015) for each transmission system combination at an ambient temperature of $25^{\circ} \mathrm{C}$ and even distribution of the load over the stroke length. To avoid overheating of the transmission system, the required power of the application $P_{a p p}$, should not exceed the permissible transmitted power.

When pre-selecting the servo motor, the following three conditions can be used, according to Bosch Rexroth (2015):

1. The rated speed of the motor must be the same as or higher than the speed required for transmission system (but not exceeding the maximum permissible value):

$$
\omega_{m, \max } \geq \omega_{t s}
$$

where

$$
\omega_{t s}=\frac{v_{r e f} 2 \pi i_{\text {gear }}}{P_{P R S}} .
$$

2. To achieve high level of control performance, the ratio of mass moments of inertia of the transmission system $J_{t s}$ and the servo motor should for handling applications satisfy:

$$
J_{r}=\frac{J_{t s}}{J_{m}+J_{b r}} \leq 6.0
$$

where $J_{m}$ and $J_{b r}$ are the mass moments of inertia of the servo motor and the motor brake.

3 . The ratio of static load moment $T_{\text {stat }}$ to the continuous torque of the servo motor $T_{0}$ must be less than or equal to the empirical value of 0.6 :

$$
T_{r}=\frac{T_{\text {stat }}}{T_{0}} \leq 0.6
$$

where

$$
T_{\text {stat }}=T_{f, e m c}+T_{m g}+T_{e q}
$$

and $T_{m g}$ is the vertical weight moment of the load, $T_{e q}$ is the equivalent dynamic torque, as expressed in the following equations:

$$
\begin{gathered}
T_{m g}=\frac{F_{m g} P_{P R S}}{2 \pi i_{\text {gear }} \eta} \\
T_{e q}=\frac{F_{m} P_{P R S}}{2 \pi i_{\text {gear }} \eta} .
\end{gathered}
$$

where $F_{m g}$ is the load of the moving masses and $\eta$ is the mechanical efficiency of the EMC drivetrain.

\subsection{Modeling of EMC Drivetrain}

In the model of the EMC drivetrain, as illustrated in Figure 8, a converter powers and controls the servo motor. The servo motor is connected to the transmission system, including the PRS and a gearbox - see Figure 9. The bodies and masses of the transmission system are included in the multibody system, as described in Section 3. 


\begin{tabular}{|c|c|c|c|}
\hline \begin{tabular}{c} 
Converter \\
\cline { 2 - 3 } $\begin{array}{c}\text { Speed } \\
\text { controller }\end{array}$
\end{tabular} & $\begin{array}{c}\text { Servo motor } \\
\text { PMSM }\end{array}$ & $\begin{array}{c}\text { Transmission system } \\
\text { PMSM }\end{array}$ & $\begin{array}{c}\text { MBS } \\
\text { Gripper } \\
\text { arm }\end{array}$ \\
\hline
\end{tabular}

Figure 8: EMC drivetrain model connected to the mechanical system.

\subsubsection{Servo Motor}

According to the catalog (Bosch Rexroth, 2015), the motor that actuates the EMC-HD is a PMSM. In this paper, the PMSM is modeled in the rotating $d q$-frame, according to Pillay and Krishnan (1989). The stator input voltages to the model $u_{s d}$ and $u_{s q}$ are obtained in the $d q$-frame from the three-phase stator voltages $u_{s a}, u_{s b}, u_{s c}$ (and vice versa) through the Park transformation $\mathbf{P}$ (and inverse transformation $\mathbf{P}^{-1}$ ), defined as (Pillay and Krishnan, 1989):

$$
\left[\begin{array}{l}
u_{s d} \\
u_{s q} \\
u_{0}
\end{array}\right]=\mathbf{P}\left[\begin{array}{l}
u_{s a} \\
u_{s b} \\
u_{s c}
\end{array}\right]
$$

where

$\mathbf{P}=\frac{2}{3}\left[\begin{array}{ccc}\cos \left(-\theta_{e}\right) & \cos \left(-\theta_{e}+\frac{2 \pi}{3}\right) & \cos \left(-\theta_{e}-\frac{2 \pi}{3}\right) \\ \sin \left(-\theta_{e}\right) & \sin \left(-\theta_{e}+\frac{2 \pi}{3}\right) & \sin \left(-\theta_{e}-\frac{2 \pi}{3}\right) \\ \frac{1}{2} & \frac{1}{2} & \frac{1}{2}\end{array}\right]$

and the transformation angle $\theta_{e}$ is the electric position representing the angle of the rotating reference frame.

The $d q$-frame is linked to the rotor and is defined as:

$$
\theta_{e}=P_{p} \theta_{r}
$$

where $P_{p}$ is the number of pole pairs. It is related to the rotor speed $\omega_{m}$, as:

$$
\omega_{e}=\frac{d \theta_{e}}{d t}=P_{p} \frac{d \theta_{r}}{d t}=P_{p} \omega_{m}
$$

The considered PMSM is modeled using the following state-space equations (Pillay and Krishnan, 1989):

$$
\begin{gathered}
\underbrace{\left[\begin{array}{c}
\dot{i}_{s d} \\
\dot{i}_{s q} \\
\dot{\omega}_{m}
\end{array}\right]}_{\dot{x}}=\mathbf{A} \underbrace{\left[\begin{array}{c}
i_{s d} \\
i_{s q} \\
\omega_{m}
\end{array}\right]}_{x}+\mathbf{B} \underbrace{\left[\begin{array}{c}
u_{s d} \\
u_{s q} \\
T_{L}
\end{array}\right]}_{u} \\
\underbrace{\left[\begin{array}{c}
i_{s d} \\
i_{s q} \\
\omega_{m}
\end{array}\right]}_{y}=\mathbf{C} \underbrace{\left[\begin{array}{c}
i_{s d} \\
i_{s q} \\
\omega_{m}
\end{array}\right]}_{x}
\end{gathered}
$$

where:

$$
\begin{gathered}
\mathbf{A}=\left[\begin{array}{ccc}
-\frac{R}{L} & P_{p} \omega_{m} & 0 \\
-P_{p} \omega_{m} & -\frac{R}{L} & 0 \\
0 & \frac{3}{2} \frac{P_{p} \Psi}{J_{t o t}} & -\frac{B_{f m}}{J_{t o t}}
\end{array}\right] \\
\mathbf{B}=\left[\begin{array}{ccc}
\frac{1}{L} & 0 & 0 \\
0 & \frac{1}{L} & 0 \\
0 & 0 & \frac{1}{J_{t o t}}
\end{array}\right] \\
\mathbf{C}=\left[\begin{array}{lll}
1 & 0 & 0 \\
0 & 1 & 0 \\
0 & 0 & 1
\end{array}\right] .
\end{gathered}
$$

It is clear that the PMSM model is nonlinear as it contains product terms such as speed $\omega_{m}$ and stator currents $i_{s d}$ and $i_{s q}$ (Pillay and Krishnan, 1989).

Values of stator resistance $R$, stator inductance $L$ and the torque constant $k_{t}$ are obtained from the cata$\log$ (Bosch Rexroth, 2006). The flux linkage $\Psi$ is then obtained from the following equation (Pillay and Krishnan, 1989):

$$
\Psi=\frac{2}{3} \frac{k_{t}}{P_{p}} .
$$

The combined mass moment of inertia $J_{t o t}$ and the combined friction moment $T_{f, e m c}$ of the PMSM and the transmission system (PRS and gearbox) reduced with reference to the motor shaft are obtained from the EMC-HD catalog (Bosch Rexroth, 2015). The friction torque is assumed to be the linear viscous friction:

$$
T_{f m}=B_{f m} \omega_{m}
$$

where

$$
B_{f m}=\frac{T_{f, e m c}}{\omega_{m, \max }} .
$$

The electromagnetic torque is:

$$
T_{e}=\frac{3}{2} P_{p} \Psi i_{s q}
$$

and the equation of motion of the rotor shaft then becomes:

$$
T_{e}=T_{L}+\underbrace{B_{f m} \omega_{m}}_{T_{f m}}+\underbrace{J_{t o t} \dot{\omega}_{m}}_{T_{a}}
$$

where $T_{L}$ is the effective torque on the transmission system and $T_{a}$ is the acceleration torque - see Figure 9 . 


\subsubsection{Transmission System}

The transmission system is driven by the electromagnetic torque. Based on Equation 37, the effective torque exerted on the servo motor is determined as:

$$
T_{L}=T_{e}-T_{f m}-T_{a}
$$

The transmission screw (PRS) transfers the rotational power into the translational form through:

$$
k_{e m c}=\frac{2 \pi}{P_{P R S}}
$$

where $k_{e m c}$ is the drive ratio and $P_{P R S}$ is the lead of the PRS.

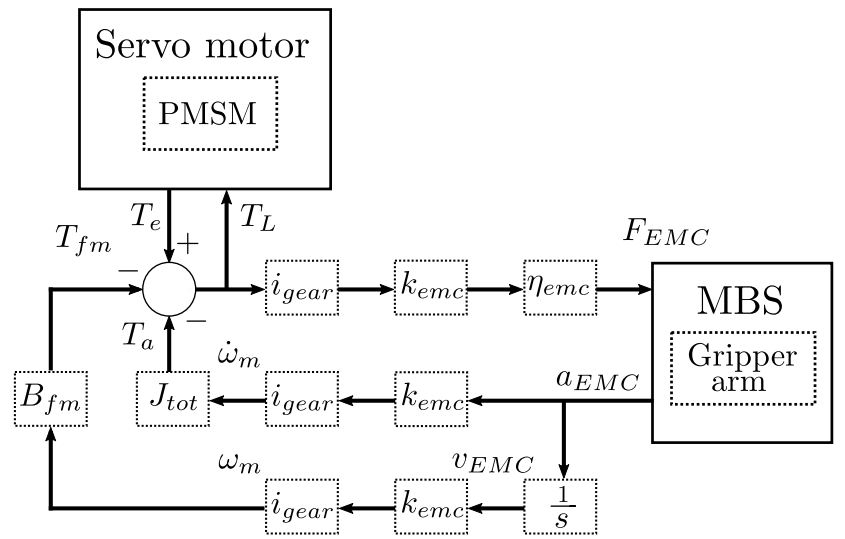

Figure 9: Transmission model sub-system.

Considering the direction dependent efficiency $\eta$, which represents the efficiency of the EMC drivetrain, the torque balance at the PRS can be derived as (Fu et al., 2015):

$$
F_{E M C}=m_{9} g+F_{9, y}
$$

where $m_{9}$ is the moving mass of the transmission system (PRS nut and cylinder rod), $g$ is the gravity, $F_{9, y}$ is the external forces connected to the cylinder rod and $F_{E M C}$ is the PRS input force connected to the gripper arm multibody system, as expressed in Equation 13, which can be written as:

$$
F_{E M C}=T_{L} i_{\text {gear }} k_{e m c} \eta
$$

where $i_{\text {gear }}$ is the gearbox ratio.

\subsection{Motion Control}

The synchronous frame-based field-oriented control is considered to be one of the most popular methods for controlling PMSMs (Wang et al., 2016). As shown in Equation 36, the electromagnetic torque of PMSM can be adjusted by exclusively controlling the current $i_{s q}$. Therefore, the reference value of $i_{s d, r e f}$ is normally set to $0 \mathrm{~A}$. Then, the reference stator currents $i_{s q, r e f}$ and $i_{s d, r e f}$ are converted to the three-phase currents and compared with the measured actual motor currents $i_{s a}, i_{s b}$, and $i_{s c}$ in the inverter/pulse width modulation (PWM) section of the torque control circuit. The torque control can be extended to the speed control by adding an external control loop. The considered speed control strategy of the PMSM is illustrated in Figure 10. In the current work, a simple PI controller is used to adjust the motor speed to a desired value.

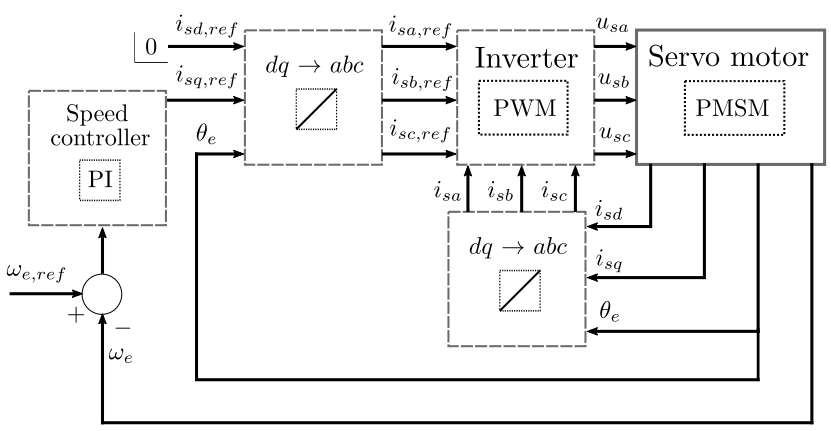

Figure 10: Field-oriented control of PMSM.

\section{Simulation Results}

In this paper, the vertical pipe handling machine gripper arm, see Figure 3, is used as a modeling and simulation case study. The gripper arm, including the hydraulic lifting cylinder and load (pipe), is numerically modeled and simulated. The kinematic response (position and velocity) of the model is compared against the hydraulically actuated gripper arm motion (extension and retraction of the lifting cylinder) of a full-scale vertical pipe handling machine logged during its operation on an offshore oil rig. In addition, the dynamic behavior of the model is investigated as well to determine the force/torque levels that have to be provided by the designed EMC drivetrain.

\subsection{Inverse Dynamic Analysis}

To determine the force that has to be delivered by the EMC drivetrain, the inverse dynamic analysis of the gripper arm is performed. The prescribed motion of the driving coordinates determines the motion of the system. This prescribed motion, i.e. position, velocity and acceleration profiles, is implemented in the longitudinal driver constraint function to represent the 
motion cycle of the hydraulic lifting cylinder, as described in Section 3.

The velocity input $v_{\text {ref }}$ shown in Figure 11 represents the controller input signal used in the real-world machine.

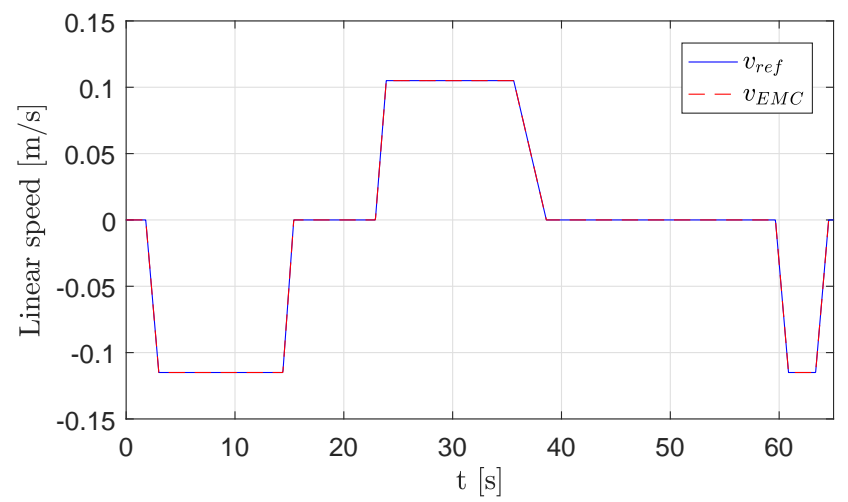

Figure 11: EMC drivetrain speed.

To verify the kinematics of the multibody system model, the horizontal reach position ( $x$-direction) of the gripper head (body 7) and the displacement of the longitudinal driver are compared against the logged position of the gripper head reference point and cylinder displacement - see Figure 12 and 13.

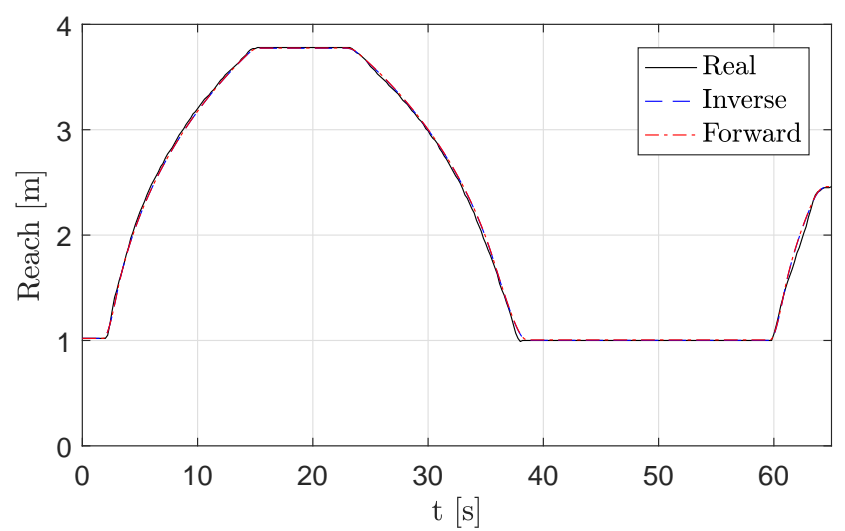

Figure 12: Gripper arm reach position.

The results show that the modeled reach position closely resembles the position of the full-scale reference machine.

The average speed over the entire cycle is found to be $v_{m, s i m}=0.0511 \frac{m}{s}$ by integrating the absolute velocities:

$$
v_{m, s i m}=\int_{t=0 s}^{t=65 s}\left|v_{m}(t)\right| d t .
$$

The average load over the entire cycle is found to be $F_{m, s i m}=25.845 k N$ by integrating the absolute forces:

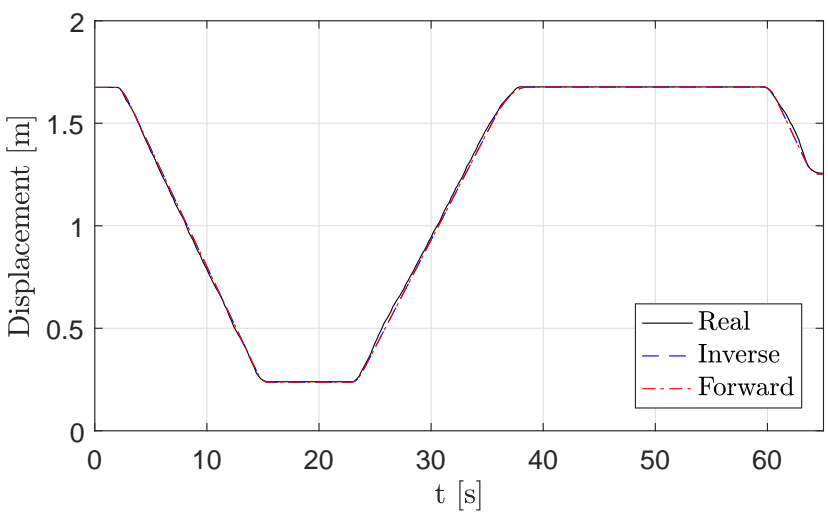

Figure 13: Lifting cylinder displacement.

$$
F_{m, s i m}=\int_{t=0 s}^{t=65 s}\left|F_{m}(t)\right| d t .
$$

The resulting reaction force in the y-direction of the longitudinal driver constraint is derived from Equation 10 and shown in Figure 14.

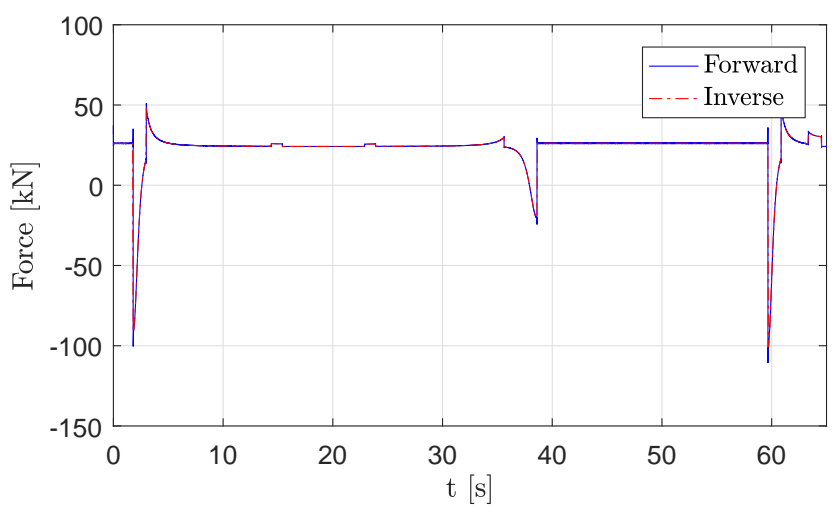

Figure 14: Lifting cylinder axial force.

The magnitude of the largest force produced by the longitudinal driver is read from Figure 14 to be $F_{\max }=100.8 \mathrm{kN}$ at $59.7 \mathrm{~s}$.

From the simulated average speed and load value from Equations 42 and 43:

$$
P_{a p p, s i m}=v_{m, s i m} F_{m, s i m}
$$

the required amount of power is calculated to be $P_{a p p, s i m}=1319.6 \mathrm{~W}$.

\subsection{EMC Drivetrain Components Selection}

For stroke lengths greater than $1.5 \mathrm{~m}$, the PRS is the only available screw transmission in the EMC-HD series from Bosch Rexroth (2015). The relevant catalog 
Table 2: EMC-HD-180 transmission system catalog data (Bosch Rexroth, 2015).

\begin{tabular}{ccccccccc}
\hline No. & $P_{P R S}[m]$ & $i_{\text {gear }}$ & $F_{\max }[k N]$ & $T_{p}[N m]$ & $\eta$ & $T_{f, e m c}[N m]$ & $v_{\max }\left[\frac{m}{s}\right]$ & $a_{\max }\left[\frac{\mathrm{m}}{\mathrm{s}^{2}}\right]$ \\
\hline 1 & 0.01 & 1 & 250.0 & 497.4 & 0.80 & 17.0 & 0.33 & 30 \\
2 & 0.01 & 3 & 250.0 & 174.5 & 0.76 & 19.7 & 0.19 & 30 \\
3 & 0.01 & 5 & 250.0 & 104.7 & 0.76 & 12.4 & 0.12 & 30 \\
4 & 0.01 & 7 & 250.0 & 74.8 & 0.76 & 9.2 & 0.08 & 30 \\
5 & 0.01 & 3 & 250.0 & 170.9 & 0.78 & 23.7 & 0.19 & 30 \\
6 & 0.01 & 5 & 250.0 & 102.5 & 0.78 & 12.9 & 0.12 & 30 \\
7 & 0.02 & 1 & 133.2 & 530.0 & 0.80 & 19.0 & 0.67 & 30 \\
8 & 0.02 & 1 & 136.4 & 650.0 & 0.80 & 19.0 & 0.67 & 30 \\
9 & 0.02 & 3 & 178.5 & 249.1 & 0.76 & 20.3 & 0.39 & 30 \\
10 & 0.02 & 5 & 178.5 & 149.5 & 0.76 & 12.8 & 0.23 & 30 \\
11 & 0.02 & 7 & 178.5 & 106.8 & 0.76 & 9.5 & 0.17 & 30 \\
12 & 0.02 & 3 & 290.0 & 396.5 & 0.78 & 24.3 & 0.39 & 30 \\
13 & 0.02 & 5 & 290.0 & 237.9 & 0.78 & 13.3 & 0.23 & 30 \\
\hline
\end{tabular}

data used for selection of the various transmission system combinations are listed in Table 2, and the relevant servo motor data are listed in Table 3.

The EMC drivetrain parameters used here are for motor attachment via flange and coupling. Three different mounting configurations (without gearbox) are illustrated in Figure 15 to compare the size of the different drivetrain configurations with the EHC system used on the full-scale reference machine.

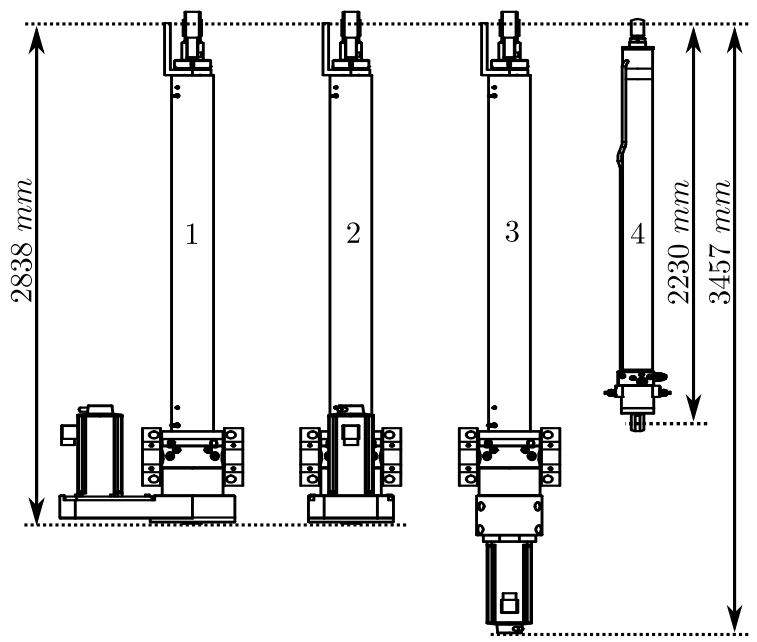

Figure 15: 1-2: motor attachment via timing belt side drive. 3: motor attachment via flange and coupling. 4: existing hydraulic cylinder.

From the servo motor pre-selection procedure described in Section 4.2, the EMC drivetrain combination that satisfies the three conditions is obtained based on the simulation results from the inverse dynamic analysis. As shown in Table 4, combination No. 3 and servo motor MSK101E-300 is the only EMC drivetrain
Table 3: IndraDyn S - servo motor MSK data (Bosch Rexroth, 2015).

\begin{tabular}{llcl}
\hline Motor & $\omega_{\max \max }\left[\frac{\mathrm{rad}}{\mathrm{s}}\right]$ & $T_{0}[\mathrm{Nm}]$ & $T_{\max }[\mathrm{Nm}]$ \\
\hline $101 \mathrm{D}-300$ & 481.7 & 50 & 160 \\
$101 \mathrm{E}-300$ & 481.7 & 70 & 231 \\
$101 \mathrm{E}-300^{1}$ & 481.7 & 105 & 231 \\
$133 \mathrm{D}-300^{1}$ & 314.2 & 152 & 320 \\
$1^{133 E-300}$ & 314.2 & 250 & 520 \\
\hline 1 With fan & & &
\end{tabular}

combination which does not require an external cooling system and satisfies the pre-selection procedure.

From the catalog (Bosch Rexroth, 2015), the dynamic load capacity of the selected EMC drivetrain is found to be $C=470 \mathrm{kN}$. Based on the average load and the presented motion cycle (Figure 11), the estimated nominal life of the EMC drivetrain in number of revolutions and hours is determined from Equations 14-16 to be $L_{10} \approx 6.0 \cdot 10^{9}$ revolutions, and $L_{10 h} \approx 3.3 \cdot 10^{5}$ hours, respectively.

All considered EMC drivetrain combinations in Table 2 satisfy the maximum permissible axial force $F_{\max }=100.8 \mathrm{kN}$. The maximum permissible transmitted power of the EMC-HD-180 is from the catalog (Bosch Rexroth, 2015) found to be $970 \mathrm{~W}$ for $P_{p}=0.01 \mathrm{~m}$ and $1240 \mathrm{~W}$ for $P_{p}=0.02 \mathrm{~m}$, both smaller than the required amount of power $P_{a p p, s i m}=1319.6 \mathrm{~W}$. Combination No. 4 does not satisfy the required linear speed from the desirable motion cycle (Figure 11), where the linear reference speeds are $v_{\text {ref }}=0.115 \frac{\mathrm{m}}{\mathrm{s}}$ when retracting and $v_{\text {ref }}=0.105 \frac{\mathrm{m}}{\mathrm{s}}$ when extending. 
Table 4: EMC drivetrain pre-selection results.

\begin{tabular}{clcll}
\hline No. & Motor & $\omega_{t s}\left[\frac{\mathrm{rad}}{\mathrm{s}}\right]$ & $J_{r}$ & $T_{r}$ \\
\hline 1 & $133 \mathrm{E}-300^{1}$ & 72.26 & 1.04 & 0.56 \\
2 & $101 \mathrm{E}-300^{1}$ & 216.77 & 1.01 & 0.59 \\
3 & $101 \mathrm{E}-300$ & 361.28 & 0.42 & 0.55 \\
3 & $101 \mathrm{E}-300^{1}$ & 361.28 & 0.42 & 0.36 \\
5 & $133 \mathrm{D}-300^{1}$ & 216.77 & 0.29 & 0.43 \\
5 & $133 \mathrm{E}-300^{1}$ & 216.77 & 0.21 & 0.26 \\
12 & $133 \mathrm{E}-300^{1}$ & 108.38 & 0.23 & 0.42 \\
13 & $133 \mathrm{D}-300^{1}$ & 180.64 & 0.13 & 0.42 \\
13 & $133 \mathrm{E}-300^{1}$ & 180.64 & 0.10 & 0.25 \\
\hline \multicolumn{5}{c}{${ }^{1}$ With fan } \\
\end{tabular}

\subsection{Forward Dynamic Analysis}

The forward dynamic analysis is used to verify that the selected EMC drivetrain can provide the required power and motion performance of the full-scale reference machine.

Based on the components selection in Section 5.2, the model parameters of combination No. 3, summarized in Table 2, and servo motor MSK101E-300 are obtained from the manufacturer catalogs: (Bosch Rexroth, 2015) and (Bosch Rexroth, 2006). For the servo motor model, the following parameters are used: winding resistance $R=0.11 \Omega$, winding inductance $L=0.19 \mathrm{mH}$ and number of pole pairs $P_{p}=4$.

In the simulation, the reference speed profile $v_{\text {ref }}$ as shown in Figure 11 is given as a reference speed input $\omega_{e, r e f}$ to the closed loop PI speed controller illustrated in Figure 10. The simulated speed $v_{E M C}$ of the EMC drivetrain is compared with $v_{r e f}$ and the results are shown in Figure 11. The deviation between $v_{E M C}$ and $v_{\text {ref }}$ is presented in Figure 16.

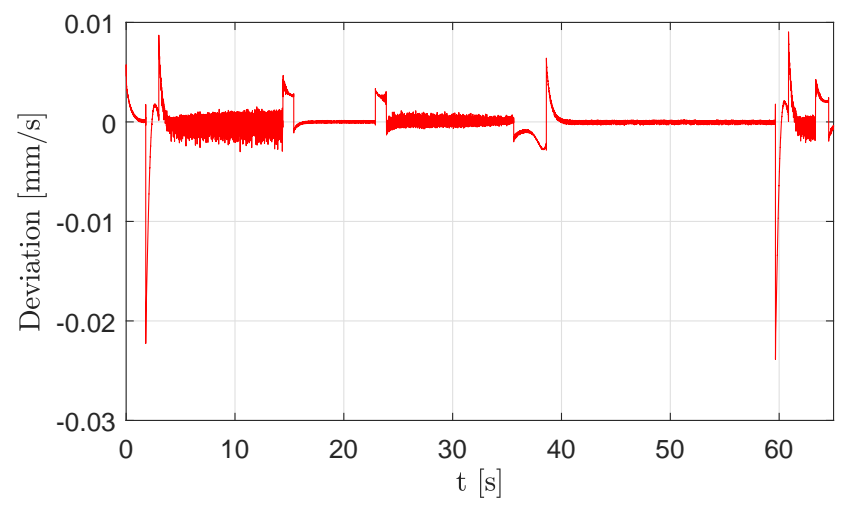

Figure 16: EMC drivetrain speed deviation.

The simulated EMC drivetrain displacement $x_{E M C}$ is compared in Figure 13 against the displacement of the EHC logged from the offshore rig in operation.
The axial force provided by the EMC drivetrain is shown in Figure 14, and the highest occurring force is $F_{E M C}=110.6 \mathrm{kN}$. The highest torque provided by the servo motor is $T_{e}=54.04 \mathrm{Nm}$, as shown in Figure 17.

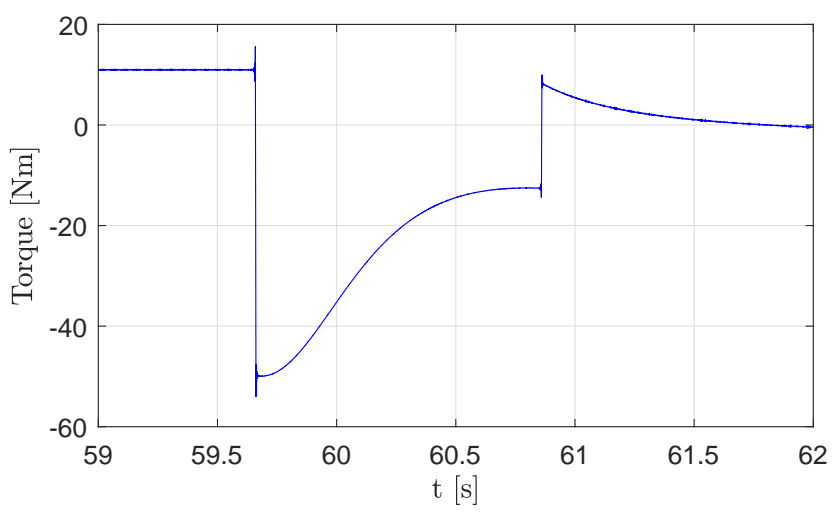

Figure 17: Electromagnetic torque of the servo motor.

The obtained results indicate that both the kinematics and dynamics of the modeled system correspond well to the performance of the full-scale reference machine. In addition, the required actuator force profiles are identical regardless if using inverse or forward dynamic analysis to determine the force/torque demand coming from the multibody system.

\section{Feasibility Analysis}

Today, the experience and knowledge of using EMC drivetrains in OMS are very subjective, and the skepticism regarding reliability is high, due to e.g. the risk of breakdown (jamming) of the transmission screw due to unexpected impact forces (shock) and overloads. Also, the availability of commercial off-the-shelf EMC drivetrains that satisfy both the explosive atmospheres (Ex) certification (i.e. complies with the ATEX Directive 2014/34/EU (European Commission, 2014)), power, motion, and safety requirements of OMS is limited. However, many manufacturers of EMC drivetrains can deliver tailor-made solutions that have potential to meet these, if not now, then most likely in the future due to research and development of EMC drivetrains design for OMS applications. Furthermore, the durability of tailor-made solutions is difficult to estimate due to lack of manufacturers experience with a customized drive.

\subsection{Motion Performance}

With a focus on the motion performance, numerical modeling and simulation based on information pro- 
vided in the manufacturer catalog (Bosch Rexroth, 2015) are used when sizing and selecting the components of the considered EMC drivetrain.

The forward dynamic analysis verifies that the selected EMC drivetrain can provide the required force, displacement, velocity, and acceleration of the full-scale reference machine. Also, the highest values obtained for axial force, motor torque, motor speed, linear speed and acceleration are within the limits of the maximum permissible values of the selected EMC drivetrain - see Figure 11-17. However, the total power required for the considered motion cycle is higher than the maximum permissible power of all the EMC drivetrain combinations listed in Table 4. Therefore, based on the recommendation of the manufacturer (Bosch Rexroth, 2015), avoidance of overheating cannot be guaranteed for the EMC drivetrain combinations investigated for the case study presented in this paper. Hence, to avoid overheating, the average speed of the motion cycle must be decreased. From the catalog (Bosch Rexroth, 2015) the permissible power is found to be higher for the transmission screw with lead $P_{p}=0.02 \mathrm{~m}(1240 \mathrm{~W})$ compared to $P_{p}=0.01 m(970 W)$. Therefore, by using an EMC drivetrain combination with $P_{p}=0.02 \mathrm{~m}$ and a servo motor with external cooling (e.g. combination No. 12 and servo motor MSK133E-300 ${ }^{1}$ ) the permissible power would be closer to match the demanded power $(1319.6 \mathrm{~W})$ than the EMC drivetrain combination simulated in Section 5.3.

\subsection{Reliability and Safety}

Research on replacing traditional hydraulic or electrohydraulic actuation in centralized hydraulic power systems with EMCs with a decentralized power system in aircraft flight control and aerospace systems are well documented in the literature, specially regarding reliability and safe operations - see for instance the work done by Bodden et al. (2007), Garcia et al. (2008), Balaban et al. (2009), and Narasimhan et al. (2010).

Replacing EHC systems with EMCs while maintaining the same level of safety is, according to Garcia et al. (2008), a major challenge when considering decreasing production and maintenance costs, the size of drives, energy consumption, and pollution emissions. Furthermore, when considering to replace EHC systems with EMCs, special attention has to be paid to avoid jamming, that is, when the screw transmission becomes stuck. However, as demonstrated by Garcia et al. (2008), safe operation and reliability of an EMC drivetrain mainly depends on the motor and the electronics, especially the inverter. Finally, Garcia et al. (2008) conclude that early failure detection, independent and fault-tolerant configurations, and high reliability of motors and electronics will allow EMCs to be used also in primary flight actuators.

In case of breakdown, OMS demand functional features that allow the drive systems to be manually controlled out of the operation zone so that the process can continue with alternative equipment. According to Schinstock and Haskew (1996), it is difficult to design an EMC drivetrain where a failed transmission screw can be disengaged from the load to allow redundant drives to take over. In comparison with the EHC system used in OMS where counterbalance valves serve safety functions for load holding, EMC drivetrains need to use fail-safe brakes to hold the load when the electrical power is lost. Also, self-ventilated electrical motors are not be be continuously operated at high loads and low speeds due to reduced cooling capacity and risk of stall conditions (Pawlus, 2016).

The ATEX Directive (European Commission, 2014) regulates usage of electrical equipment in the hazardous areas, e.g. area around the well center, and it also defines health and safety requirements of OMS. Consequently, this limits the number of available EMC drivetrain components e.g. electrical motors, converters, gearboxes, transmissions screws, hydraulic valves, hydraulic pumps, etc. Since only components that are Ex certified can be used in OMS, the design process becomes more challenging, and it might turn out that the solutions which satisfy the performance requirements and design criteria do not comply with the ATEX Directive, according to Pawlus (2016).

\subsection{Durability}

A test performed by Schinstock and Haskew (1996) demonstrates that roller screws (SKF set with a nonpreloaded nut, a $48 \mathrm{~mm}$ nominal diameter screw, and $20 \mathrm{~mm}$ lead) may be damaged by dynamic loading with load magnitudes well within the static load rating of the screw. Schinstock and Haskew (1996) concludes that while this damage is not catastrophic, it would defeat one of the main goals of the replacement of the EHC system with EMC drivetrain. Furthermore, it would be expected that the damaged portions of the thread face would begin to flake and deteriorate and substantially decrease the life of the screw. However, the results presented by Schinstock and Haskew (1996) do not prohibit the use of roller screws in harsh applications. Rather, they emphasize the critical importance of good dynamic analysis of the loads generated by an application and good controller design. Also, Schinstock and Haskew (1996) emphasizes the point that the actuator must be back-drivable and include some sort of force limiting control in such applications.

According to Garcia et al. (2008), condition monitoring is receiving a remarkable deal of attention in the field of aeronautics, as it can detect incipient faults 
at an early stage. This reduces the maintenance and down-time expense, and also improves operation safety. This is why carriers and flight companies are more interested than ever in the adoption of new conditionmonitoring techniques. Preferably, online techniques for predictive maintenance, to check and evaluate performance conditions of both the rotating electrical machines and the whole electronics.

The speed reference control signal used in the analysis presented in this paper is of trapezoidal shape - see Figure 11. According to Pawlus et al. (2016b), trapezoidal profiles cause overshoots, induce residual vibrations and can generate high peak loads. As an alternative reference profile, trigonometric profiles are investigated by Pawlus et al. (2016b) and prove to reduce torque peak values by up to $50 \%$, remove jerk discontinuities and provide smoother machine operation. Jerk control allows to ensure smooth accelerations, vibrations mitigation and decreased maintenance. This is particularly important from the practical point of view, since the solution to lower the associated fatigue and vibration damage is to use smooth motion profiles which are tailor-made for a given application, rather than invest in costly condition based maintenance (CBM) schemes or implement hardware modifications to the machine.

\subsection{Summary}

Based on the above literature survey, it is concluded that an EMC drivetrain:

- offers good energy-efficiency, simple installation (plug and play), low maintenance, high stiffness (accuracy) and low space requirements in comparison to EHC systems with HPU and power lines (Michel and Weber, 2012)

- has low durability at high load force due to wear, and has little overload protection against shock loads (Michel and Weber, 2012)

- is an appealing alternative to EHC system, since it allows for the elimination of local hydraulic circuits, implying a significant maintenance cost reduction due to the absence of wearing parts such as seals, hence, eliminates fluid spills (Garcia et al., 2008)

- demands electric power just when it is needed, compared to centralized powered EHC systems where a continuous load on the HPU must be ensured regardless if the hydraulic power is used for actuation or not (Garcia et al., 2008)
- is relatively compact and can offer high power-toweight ratios and motion velocities (Balaban et al., 2009)

- with a roller screw can be used for both highly and less accurate movement with flexible leads and desired precision (Hojjat and Mahdi Agheli, 2009)

- has high static load capabilities, however, the permissible transmitted power causes limitations on the allowable linear speed at high loads

- with large displacement and high load capabilities certified for explosive atmosphere areas is limited in availability.

\section{Conclusion}

This paper presents a feasibility study of the implementation of an EMC drivetrain in an offshore vertical pipe handling machine. The EMC-HD from Bosch Rexroth (2015) is considered as one of the commercial off-the-shelf EMC drivetrains which closely can match the power (static and dynamic force) and motion performance (displacement length and speed) demand of the case study machine.

From the inverse dynamic analysis, the EMC drivetrain components are selected based on the sizing principles and selection procedure of the manufacturer. The forward dynamic analysis verifies that the performance of the selected EMC drivetrain satisfies the requirements of the full-scale reference machine. The highest values obtained for axial force, motor torque, motor speed, linear speed and acceleration are within the limits of the maximum permissible values of the selected EMC drivetrain. However, the permissible transmitted power of the EMC drivetrain is lower than the power required by the motion cycle. Hence, based on the manufacturers recommendations, avoidance of overheating in the EMC drivetrain cannot be guaranteed. To avoid overheating, the average speed of the motion cycle must be decreased. Alternatively, external cooling or temperature monitoring and control system that prevents overheating could be implemented. Also, a transmission screw designed with larger lead can increase the permissible power of the EMC drivetrain.

Commercial off-the-shelf EMC drivetrains with large displacement and high load capabilities certified for explosive atmosphere areas are very limited or do not currently exist in the form that would allow to meet the requirements of a typical offshore drilling equipment. Where, design criteria such as temperature condition (typically $+40^{\circ} \mathrm{C}$ to $-20^{\circ} \mathrm{C}$ ), IP protection class, reliability, safety, and durability need to be satisfied. 
Even though these systems are not commercially available, this paper shows that once the power and Exapproval problems are solved, EMC drivetrains might become strong competitors to hydraulic cylinders in offshore drilling equipment systems where centralized hydraulic power is not available.

\section{Acknowledgments}

The research presented in this paper has received funding from the Norwegian Research Council, SFI Offshore Mechatronics, project number 237896.

\section{References}

Austigard, A. Robotic Drilling Systems. http://rds . no, 2016. Accessed: 2017-03-03.

Bak, M. K. Model Based Design of Electro-Hydraulic Motion Control Systems for Offshore Pipe Handling Equipment. Ph.D. thesis, University of Agder, 2014.

Bak, M. K. and Hansen, M. R. Analysis of Offshore Knuckle Boom Crane - Part One: Modeling and Parameter Identification. Modeling, Identification and Control: A Norwegian Research Bulletin, 2013. 34(4):157-174. doi:10.4173/mic.2013.4.1.

Balaban, E., Bansal, P., Stoelting, P., Saxena, A., Goebel, K. F., and Curran, S. A diagnostic approach for electro-mechanical actuators in aerospace systems. In 2009 IEEE Aerospace conference. IEEE, pages 1-13, 2009. doi:10.1109/AERO.2009.4839661.

Bodden, D. S., Clements, N. S., Schley, B., and Jenney, G. Seeded Failure Testing and Analysis of an Electro-Mechanical Actuator. In 2007 IEEE Aerospace Conference. IEEE, pages 1-8, 2007. doi:10.1109/AERO.2007.352880.

Bosch Rexroth. IndraDyn S - MSK Project Planning Manual. 2006.

Bosch Rexroth. Electrical Mechanical Cylinder EMCHD Catalog. 2015.

Couper, J. R., Penney, W. R., Fair, J. R., and Walas, S. M. Chemical Process Equipment - Selection and Design. Elsevier, 3rd edition edition, 2012.

European Commission. Directive 2014/34/EU of the European Parliament and of the Council. Official Journal of the European Union L96, 2014.

Frischemeier, S. Electrohydrostatic actuators for aircraft primary flight control-types, modelling and evaluation. In 5th Scandinavian International Conference on Fluid Power, SICFP '97, Linköping, Sweden, May 28. -30. pages 1-16, 1997. doi:10.15480/882.236.

Fu, Y., Wang, D., Chen, J., Yang, R., and Qi, X. Nonlinear Modeling and System Analysis of the Linear Electromechanical Actuators Deviation of Nonlinear Dynamic Modeling. Journal of Computational Information Systems, 2015. 6(11):1983-1995. doi:10.12733/jcis13671.

Gallant, T. A. and Andrews, K. M. Large cage induction motors for offshore machinery drive applications. In Petroleum and Chemical Industry Conference. pages 1155-1159, 2006.

Garcia, A., Cusido, J., Rosero, J., Ortega, J., and Romeral, L. Reliable electro-mechanical actuators in aircraft. IEEE Aerospace and Electronic Systems Magazine, 2008. 23(8):19-25. doi:10.1109/MAES.2008.4607895.

Hoevenaars, A. H., Evans, I. C., and Desai, B. Preventing AC drive failures due to commutation notches on a drilling rig. IEEE Transactions on Industry Applications, 2013. 49(3):1215-1220. doi:10.1109/TIA.2013.2253078.

Hojjat, Y. and Mahdi Agheli, M. A comprehensive study on capabilities and limitations of rollerscrew with emphasis on slip tendency. Mechanism and Machine Theory, 2009. 44(10):1887-1899. doi:10.1016/j.mechmachtheory.2009.04.001.

Holm, R. K., Berg, N. I., Walkusch, M., Rasmussen, P. O., and Hansen, R. H. Design of a magnetic lead screw for wave energy conversion. IEEE Transactions on Industry Applications, 2013. 49(6):26992708. doi:10.1109/TIA.2013.2264272.

Isermann, R., Schwarz, R., and Stolzl, S. Fault-tolerant drive-by-wire systems. IEEE Control Systems, 2002. 22(5):64-81. doi:10.1109/MCS.2002.1035218.

Kandukuri, S. T., Klausen, A., Karimi, H. R., and Robbersmyr, K. G. A review of diagnostics and prognostics of low-speed machinery towards wind turbine farm-level health management. Renewable and Sustainable Energy Reviews, 2016. 53:697 - 708. doi:10.1016/j.rser.2015.08.061.

Lemor, P. The roller screw, an efficient and reliable mechanical component of electro-mechanical actuators. In IECEC 96. Proceedings of the 31st Intersociety Energy Conversion Engineering Conference, volume 1. IEEE, pages 215-220, 1996. doi:10.1109/IECEC.1996.552873. 
Michel, S. and Weber, J. Energy-efficient electrohydraulic compact drives for low power applications. Fluid Power and Motion Control (FPMC 2012), 2012. pages 94-108.

Narasimhan, S., Roychoudhury, I., Balaban, E., and Saxena, A. Combining Model-Based and FeatureDrivenFeature-Driven Diagnosis Approaches A Case Study on Electromechanical Actuators. 21st International Workshop on Principles of Diagnosis, 2010. pages 1-9.

Neleman, K. Motor controls for Ex motors in hazardous areas: An application guide! In 2009 Conference Record PCIC Europe. pages 132-145, 2009.

Nikravesh, P. E. COMPUTER-AIDED ANALYSIS OF MECHANICAL SYSTEMS. Prentice Hall, 1988.

Nikravesh, P. E. PLANAR MULTIBODY DYNAMICS. CRC Press - Taylor \& Francis Group, 2008.

Ottestad, M., Nilsen, N., and Hansen, M. Reducing the static friction in hydraulic cylinders by maintaining relative velocity between piston and cylinder. In International Conference on Control, Automation and Systems. pages 764-769, 2012.

Parker. Extreme Force Electromechanical Cylinder Catalog. 2013.

Pawlus, W. Design and Analysis of Electric Powertrains for Offshore Drilling Applications. Ph.D. thesis, University of Agder, 2016.

Pawlus, W., Choux, M., and Hansen, M. R. Hydraulic vs. electric: A review of actuation systems in offshore drilling equipment. Modeling, Identification and Control, 2016a. 37(1):1-17. doi:10.4173/mic.2016.1.1.

Pawlus, W., Frick, D., Morari, M., Hovland, G., and Choux, M. Drivetrain design optimization for electrically actuated systems via Mixed Integer Programing. In Industrial Electronics Society, IECON 2015 - 41st Annual Conference of the IEEE. pages 14651470, 2015. doi:10.1109/IECON.2015.7392307.

Pawlus, W., Hansen, M. R., Choux, M., and Hovland, G. Mitigation of fatigue damage and vibration severity of electric drivetrains by systematic selection of motion profiles. IEEE/ASME Transactions on Mechatronics, 2016b. 21(6):2870-2880. doi:10.1109/TMECH.2016.2573587.

Pawlus, W., Khang, H. V., and Hansen, M. Temperature rise estimation of induction motor drives based on loadability curves to facilitate design of electric powertrains. IEEE Transactions on Industrial Informatics, 2016c. doi:10.1109/TII.2016.2641454. In Press.

Pillay, P. and Krishnan, R. Modeling, simulation, and analysis of permanent-magnet motor drives. The permanent-magnet synchronous motor drive. Industry Applications, IEEE Transactions on, 1989. 25(2):265-273. doi:10.1109/28.25541.

Rahimi, M., Rausand, M., and Wu, S. Reliability prediction of offshore oil and gas equipment for use in an Arctic environment. In International Conference on Quality, Reliability, Risk, Maintenance, and Safety Engineering. pages 81-86, 2011.

Sakuraba, J., Hata, F., Kung, C. C., Sotooka, K., Mori, H., and Takarada, N. Development of superconducting electric ship propulsion system. In The Second International Offshore and Polar Engineering Conference. pages 1-7, 1992.

Schinstock, D. and Haskew, T. Dynamic load testing of roller screw EMAs. In IECEC 96. Proceedings of the 31st Intersociety Energy Conversion Engineering Conference, volume 1. IEEE, pages 221-226, 1996. doi:10.1109/IECEC.1996.552874.

Sørensen, J. K. Reduction of Oscillations in Hydraulically Actuated Knuckle Boom Cranes. Ph.D. thesis, University of Agder, 2016.

Ummaneni, R. B., Nilssen, R., and Brennvall, J. E. Force analysis in design of high power linear permanent magnet actuator with gas springs in drilling applications. In Electric Machines Drives Conference, 200\%. IEMDC '0\%. IEEE International. pages 285-288, 2007. doi:10.1109/IEMDC.2007.382680.

Wang, Z., Chen, J., Cheng, M., and Chau, K. T. Field-oriented control and direct torque control for paralleled vsis fed pmsm drives with variable switching frequencies. IEEE Transactions on Power Electronics, $2016 . \quad 31(3): 2417-2428$. doi:10.1109/TPEL.2015.2437893.

Yadav, P., Kumar, R., Panda, S. K., and Chang, C. S. Optimal thrust allocation for semisubmersible oil rig platforms using improved harmony search algorithm. IEEE Journal of Oceanic Engineering, 2014. 39(3):526-539. doi:10.1109/JOE.2013.2270017. 